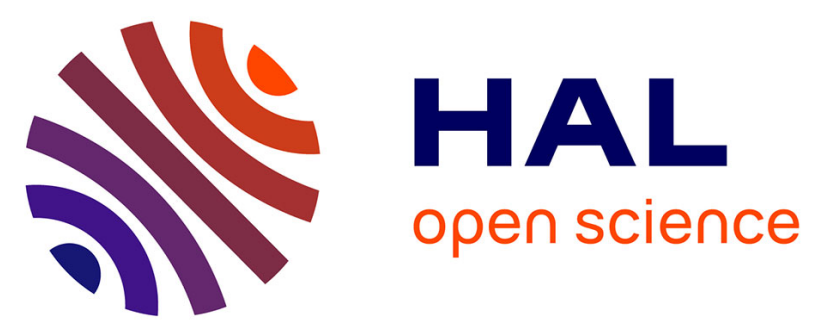

\title{
Isolation and characterization of six peach cDNAs encoding key proteins in organic acid metabolism and solute accumulation: involvement in regulating peach fruit acidity
}

Christelle Etienne, Annick Moing, Elisabeth Dirlewanger, Philippe Raymond, René Monet, Christophe Rothan

\section{To cite this version:}

Christelle Etienne, Annick Moing, Elisabeth Dirlewanger, Philippe Raymond, René Monet, et al.. Isolation and characterization of six peach cDNAs encoding key proteins in organic acid metabolism and solute accumulation: involvement in regulating peach fruit acidity. Physiologia Plantarum, 2002, 114, pp.259-270. 10.1034/j.1399-3054.2002.1140212.x . hal-02674641

\section{HAL Id: hal-02674641 \\ https://hal.inrae.fr/hal-02674641}

Submitted on 23 Aug 2021

HAL is a multi-disciplinary open access archive for the deposit and dissemination of scientific research documents, whether they are published or not. The documents may come from teaching and research institutions in France or abroad, or from public or private research centers.
L'archive ouverte pluridisciplinaire HAL, est destinée au dépôt et à la diffusion de documents scientifiques de niveau recherche, publiés ou non, émanant des établissements d'enseignement et de recherche français ou étrangers, des laboratoires publics ou privés.

\section{(c)(1)}

Distributed under a Creative Commons Attribution| 4.0 International License 


\title{
Isolation and characterization of six peach cDNAs encoding key proteins in organic acid metabolism and solute accumulation: involvement in regulating peach fruit acidity
}

\author{
Christelle Etienne ${ }^{a}$, Annick Moinga ${ }^{a}$ Elisabeth Dirlewanger ${ }^{a}$, Philippe Raymond ${ }^{b}$, René Monet ${ }^{a}$ and \\ Christophe Rothan ${ }^{\text {b,* }}$ \\ ${ }^{a}$ Unité de Recherches sur les Espèces Fruitières et la Vigne, Institut National de la Recherche Agronomique, Centre de Bordeaux, BP 81, F- \\ 33883 Villenave d'Ornon, Cedex, France \\ ${ }^{\mathrm{b}}$ Unité de Physiologie Végétale, UMR PBV, Institut National de la Recherche Agronomique, Centre de Bordeaux, BP 81, F-33883 Villenave \\ d'Ornon, Cedex, France \\ *Corresponding author, e-mail: rothan@bordeaux.inra.fr
}

\begin{abstract}
As in many other fleshy fruits, the predominant organic acids in ripe peach (Prunus persica (L.) Batsch) fruit are malic and citric acids. The accumulation of these metabolites in fruit flesh is regulated during fruit development. Six peach fruitrelated genes implicated in organic acid metabolism (mitochondrial citrate synthase; cytosolic NAD-dependent malate dehydrogenase, and cytosolic NADP-dependent isocitrate dehydrogenase) and storage (vacuolar proton translocating pumps: one vacuolar $\mathrm{H}^{+}$-ATPase, and two vacuolar $\mathrm{H}^{+}$-pyrophosphatases) were cloned. Five of these peach genes were homologous to genes isolated from fruit in other fleshy fruit species. Phylogenetic and expression analyses suggested the existence of a particular vacuolar pyrophosphatase highly expressed in fruit. The sixth gene was the first cytosolic NAD-
\end{abstract}

\section{Introduction}

Organic acids are important attributes of fruit flavour and, as such, contribute with soluble sugars and aromas to the overall organoleptic quality of fresh market peaches (Sweeney et al. 1970). The predominant organic acids in ripe peach fruit are malic and citric acids, whilst quinic acid accumulates in lower amounts (Moing et al. 1998). As in most other fleshy fruits, organic acid accumulation takes place during the early development of peach fruit (Monselise 1986, Tucker 1993). Malic acid accumulates mostly during the first rapid growth phase that occurs at the end of the cell division phase (Masia et al. 1992), whereas citric acid accumulates during the dependent malate dehydrogenase gene isolated from fruit. Gene expression was studied during the fruit development of two peach cultivars, a normal-acid (Fantasia) and a low-acid (Jalousia) cultivar. The overall expression patterns of the organic acid-related genes appeared strikingly similar for the two cultivars. The genes involved in organic acid metabolism showed a stronger expression in ripening fruit than during the earlier phases of development, but their expression patterns were not necessarily correlated with the changes in organic acid contents. The tonoplast proton pumps showed a biphasic expression pattern more consistent with the patterns of organic acid accumulation, and the tonoplast pyrophosphatases were more highly expressed in the fruit of the low-acid cultivar during the second rapid growth phase of the fruit.

Abbreviations - ACO, aconitase; CS, citrate synthase; DAB, days after full bloom; NAD-MDH, NAD-dependent malate dehydrogenase; NADPICDH, NADP-dependent isocitrate dehydrogenase; NADP-ME, NADP-dependent malic enzyme; PEPC, phosphoenolpyruvate carboxylase; RT, reverse transcription; V-ATPase, vacuolar $\mathrm{H}^{+}$-ATPase; V-PPase,vacuolar, $\mathrm{H}^{+}$-pyrophosphatase. 
cated in malic acid synthesis in the cytosol, while mitochondrial citrate synthase [CS, EC 4.1.3.7 (Popova and Pinheiro de Carvalho 1998)] and mitochondrial aconitase [ACO, EC 4.2.1.3 (Sadka et al. 2000b)] are implicated in citric acid accumulation. Malic acid degradation during ripening is mainly attributed to cytosolic NADP-dependent malic enzyme [NADP-ME; EC 1.1.1.40 (Ruffner 1982)] while cytosolic aconitase and NADP-dependent isocitrate dehydrogenase (NADP-ICDH; EC 1.1.1.42) are both involved in citric acid catabolism (Popova and Pinheiro de Carvalho 1998). The accumulation of malic and citric acids in cells is also controlled through vacuolar storage (Martinoia and Ratajczak 1998). Although the precise mechanism of the transport of organic acids inside the vacuole remains largely unknown (Barkla and Pantoja 1996, Barbier-Brygoo et al. 2000), the electrochemical gradient for $\mathrm{H}^{+}$across the tonoplast established by vacuolar $\mathrm{H}^{+}$-ATPase [V-ATPase; EC 3.6.1.3. (Ratajczak 2000)] and vacuolar $\mathrm{H}^{+}$-pyrophosphatase [V-PPase; EC 3.6.1.1. (Maeshima 2000)], the two types of proton-translocating pumps present in the tonoplast of fruit cells (Oleski et al. 1987, Müller et al. 1996, Terrier et al. 1998, Suzuki et al. 1999), is believed to play a predominant role in the storage of organic acids in the vacuole.

In tomato, the inheritance of fruit acidity was shown to be polygenic (Fulton et al. 2000, Saliba-Colombani et al. 2001). However, in several fruit species [peach (Yoshida, 1970), grape (Boubals et al. 1971), pummelo (Cameron and Soost 1977), and apple (Visser and Verhaegh 1978)], including tomato (Stevens 1972), the identification of low-acid varieties revealed the effect of a major gene governing acidity in each species. Genetic studies conducted in the species which accumulate both malic and citric acids (tomato) or which accumulate only one major organic acid, either malic acid (apple) or citric acid (pummelo), have shown that malic and citric acids are each governed by a major gene (Stevens 1972, Fang et al. 1997, Maliepaard et al. 1998). In peach, fruit low-acidity is governed by a major dominant gene (Monet 1979). Fruits from a low-acid peach cultivar exhibit a marked reduction in malic and citric acid contents (Moing et al. 1998) which is not accounted for by variations in expression or activity of PEPC (Moing et al. 2000). In Citrus fruits, the low-acid character has been widely studied in terms of physiology (Canel et al. 1995, Müller et al. 1996, Sadka et al. 2000a, 2000b), and genetic studies showed that low acidity is recessive (Fang et al. 1997). As low acidity in peach is dominant, the physiological mechanism determining low acidity in peach should be different from that in Citrus.

The aim of the present study was to screen known genes putatively involved in the control of organic acid accumulation in peach fruit. For this purpose, variations in expression during fruit development in relation to organic acid accumulation, or between normal-acid and low-acid fruits in relation to the low-acid peach phenotype, were determined. Here we report for the first time, the cloning and characterization of six peach fruit-re- lated genes encoding enzymes involved in the metabolism or storage of organic acids, and present a comprehensive study of their expression in fruits of normalacid and low-acid cultivars.

\section{Materials and methods}

\section{Plant material}

Fantasia and Jalousia peach (Prunus persica (L.) Batsch) cultivars grafted on Rubira (P. persica) rootstock were grown in a greenhouse as described previously (Moing et al. 2000). Trees from both cultivars were in their fifth growing season. Fruit growth was estimated by measuring the diameter of 12 fruits weekly, from 20 days after bloom (DAB) to fruit maturity (Fantasia, 124-126 DAB; Jalousia, 128-130 DAB). Young folded leaves were collected 20 days after tree full-bloom. Flower buds (coloured closed flowers) were collected 3 days before tree full-bloom. Fruits were harvested about every 3 weeks, at the indicated developmental stages, ranging from cell division phase to maturity, according to fruit age (DAB) and diameter (eliminating fruits with diameter more than $5 \%$ higher or lower than diameter mean). Maturity was determined according to softening. Freshly harvested plant material (young leaves, flower buds and fruits) was frozen in liquid nitrogen and stored at $-80^{\circ} \mathrm{C}$ until use.

\section{Sugar and organic acid analysis}

For each cultivar, 4 fruits were picked on the tree at the indicated developmental stages, from 20 DAB to fruit maturity. For each individual fruit, soluble sugar and organic acid contents were determined using $0.5-1 \mathrm{~g}$ of mesocarp (0.2 $\mathrm{g}$ at $20 \mathrm{DAB})$ frozen powder as described previously (Moing et al. 1998). DW was determined using $0.5-1 \mathrm{~g}$ of fresh mesocarp of 5 other fruits and drying at $60^{\circ} \mathrm{C}$ until constant weight.

\section{RNA extraction}

For RNA extraction, each fruit sample was obtained from pooled mesocarp plus epidermis of 4 fruits. Total RNA was extracted from fruit mesocarp plus epidermis, young leaves and flower buds following the method described previously (Moing et al. 2000) with modifications. The hot phenol $\left(80^{\circ} \mathrm{C}\right)$ extraction buffer $(100$ $\mathrm{m} M$ LiCl, $100 \mathrm{~m} M$ Tris-HCl, pH 8.0, 10 m $M$ EDTA, 1\% [w/v] SDS/phenol, [1:1, v:v]) was added at a ratio of 10 $\mathrm{mlg}^{-1}$ tissue. After homogenization for $1 \mathrm{~min}$ with a Polytron (Kinematica, Luzern, Switzerland) at medium setting, and centrifugation of the mixture at $40000 \mathrm{~g}$ for $15 \mathrm{~min}$, the top aqueous phase was transferred to a fresh tube, mixed 2 min with an equal volume of chloroform, and centrifuged again to separate phases. The aqueous phase was removed and extraction was repeated with an equal volume of chloroform: isoamyl alcohol (24:1, v/ 
Table 1. Set of PCR primers used to amplify peach cDNAs and corresponding size of the amplified products. Genes are listed according to the biochemical pathways in which the encoded gene products act. ${ }^{\mathrm{a}} \mathrm{F}, \mathrm{F} 1$ and $\mathrm{F} 2$ are the forward primers and $\mathrm{R}$ is the reverse primer. I = inosine; $\mathrm{M}=\mathrm{A} / \mathrm{C} ; \mathrm{N}=\mathrm{A} / \mathrm{C} / \mathrm{G} / \mathrm{T} ; \mathrm{R}=\mathrm{A} / \mathrm{G} ; \mathrm{Y}=\mathrm{C} / \mathrm{T} ; \mathrm{W}=\mathrm{A} / \mathrm{T}$. ${ }^{\mathrm{b}}$ indicates the optimal annealing temperature in ${ }^{\circ} \mathrm{C}$ for each pair of primers.

\begin{tabular}{|c|c|c|c|c|}
\hline Genes grouped according to function & & Primers $^{\mathrm{a}}$ & $\begin{array}{l}\text { Expected } \\
\text { size (bp) }\end{array}$ & $\mathrm{Tm}^{\mathrm{b}}$ \\
\hline $\begin{array}{l}\text { Malic acid metabolism } \\
\text { Cytosolic NAD-dependent malate dehydrogenase }\end{array}$ & $\begin{array}{l}\mathrm{F} 1 \\
\mathrm{~F} 2 \\
\mathrm{R}\end{array}$ & $\begin{array}{l}\text { 5'-GTI ATG GTI GGI TTY CC-3' } \\
\text { 5'-GAR GGI ATG GAR MGI AAR GAY GT -3' } \\
\text { 5'-GAY GAY GCI TGG YTI AAY GG-3' }\end{array}$ & $\begin{array}{l}408 \\
381\end{array}$ & 40 \\
\hline $\begin{array}{l}\text { Citric acid metabolism } \\
\text { Mitochondrial citrate synthase }\end{array}$ & $\begin{array}{l}\text { F1 } \\
\text { F2 } \\
\text { R }\end{array}$ & $\begin{array}{l}\text { 5'-GGI GGI ATG MGI GGI ATG AC-3' } \\
5^{\prime} \text {-GCI CAY CCI ATG ACI CAR TTY GC-3' } \\
5^{\prime} \text {-CCI TGG CI AAY GTI GAY GC-3' }\end{array}$ & $\begin{array}{l}981 \\
717\end{array}$ & 42 \\
\hline $\begin{array}{l}\text { Cytosolic NADP-dependent isocitrate } \\
\text { dehydrogenase }\end{array}$ & $\begin{array}{l}\mathrm{F} \\
\mathrm{R}\end{array}$ & $\begin{array}{l}\text { 5'-GTI GCI GGI TGG WSI AAR CC-3' } \\
5^{\prime} \text {-GTN TGG GCN TGY AAR AAY TAY G-3' }\end{array}$ & 456 & 42 \\
\hline $\begin{array}{l}\text { Vacuolar proton translocating pumps } \\
\text { Vacuolar } \mathrm{H}+- \text { ATPase catalytic subunit A }\end{array}$ & $\begin{array}{l}\text { F1 } \\
\text { F2 } \\
\text { R }\end{array}$ & $\begin{array}{l}\text { 5'-CAR GTI TAY GAR ACI GCI G-3' } \\
\text { 5'-TGG CCI GTI MGN ACN CC-3' } \\
\text { 5'-GTI TGG ATG ATG CGI AAY AT-3' }\end{array}$ & $\begin{array}{l}1442 \\
1011\end{array}$ & 42 \\
\hline Vacuolar $\mathrm{H}+-$ pyrophosphatase & $\begin{array}{l}\mathrm{F} 1 \\
\mathrm{~F} 2 \\
\mathrm{R}\end{array}$ & $\begin{array}{l}5^{\prime} \text {-GGI ATG AAR ATH GCI ACI TAY }-3^{\prime} \\
5^{\prime} \text {-TAY GGI GAY GAY TGG GAR GG - } 3^{\prime} \\
5^{\prime} \text {-GGI GCI TGG GAY AAY GCI AAR AA-3' }\end{array}$ & $\begin{array}{l}1593 \\
1452\end{array}$ & 50 \\
\hline
\end{tabular}

v). The aqueous phase was further mixed 2 min with an equal volume of ethylene glycol monobutyl ether and 0.08 volume of $3 M$ diethyl pyrocarbonate (DEPC)treated sodium acetate $\mathrm{pH}$ 5.2, and incubated on ice for at least $4 \mathrm{~h}$. The nucleic acid pellet was recovered by centrifugation at $40000 \mathrm{~g}$ for $30 \mathrm{~min}$, rinsed with $70 \%$ ethanol, and resuspended in $1 \mathrm{ml}$ of DEPC-treated $\mathrm{H}_{2} \mathrm{O}$. RNA was precipitated overnight at $4^{\circ} \mathrm{C}$ by adding 0.3 volume of $8 M$ DEPC-treated $\mathrm{LiCl}$. The RNA pellet was recovered by centrifugation at $20000 \mathrm{~g}$ for $30 \mathrm{~min}$, air dried, then dissolved in DEPC-treated $\mathrm{H}_{2} \mathrm{O}$. Total RNA samples were treated with RQ1 RNase-Free DNase (Promega, Lyon, France) for $15 \mathrm{~min}$ at $37^{\circ} \mathrm{C}$, phenolchloroform extracted, ethanol precipitated and resuspended in DEPC-treated water.

\section{Isolation of cDNA probes for organic acid-related genes}

Degenerate primers were designed from the conserved protein domains found in the corresponding sequences available for each gene using the ClustalW (http://bioweb.pasteur.fr/seqanal/interfaces/clustalw) and BlockMaker (http: // http: //www.blocks.fhcrc.org/blockmkr/make_ blocks.html) softwares. Primer sequences and annealing temperatures are listed in Table 1. RT-PCR was performed on total RNA from Fantasia fruit tissues (mesocarp plus epidermis) harvested at $45 \mathrm{DAB}$, as described previously (Moing et al. 2000). RT reaction $(20 \mu \mathrm{l})$ was primed with the reverse primer in the presence of 100 units of MMLV reverse transcriptase (Invitrogen, Cergy Pontoise). One-half of the RT reaction $(10 \mu \mathrm{l})$ was used to PCR-amplify partial cDNAs using the indicated forward and reverse primers (Table 1 ) in $50 \mu 1$ reaction volume. Two $\mu$ l of the resulting PCR product were then subjected to a second round of PCR amplification using nested forward and reverse primers. Single bands of the expected size were purified on spin columns (Sephacryl
S-400 microspin columns, Pharmacia, Uppsala, Sweden) and cloned into pGEM-T vector (Promega) which was used to transform E. coli XL1-blue electrocompetent cells. For each gene, 10 clones, found positive after PCRamplification of the bacterial colonies with degenerate primers, were further screened. For each clone, a sequencing reaction (ThermoSequenase Cycle Sequencing Kit, Amersham-Pharmacia Biotech., Saclay, France) using only one ddNTP was performed and run on a sequencing gel. Clones showing the same gel profile were grouped and one representative clone was sequenced.

\section{cDNA library construction and screening}

Total RNA prepared from 30 DAB Fantasia fruits was used to isolate poly(A) ${ }^{+}$mRNA (PolyA $\operatorname{spin}^{\mathrm{TM}}$ mRNA isolation kit; New England Biolabs, Beverly, MA, USA). Double-stranded cDNAs were synthesized from $5 \mu \mathrm{g}$ of poly $(\mathrm{A})^{+}$mRNA, ligated into Uni-ZAP ${ }^{\mathrm{TM}} \mathrm{XR}$ vector using the ZAP-cDNA synthesis kit (Stratagene, La Jolla, CA, USA) and packaged into bacteriophage using packaging extracts (Gigapack II, Stratagene) to produce the cDNA library stock, following the manufacturer's instructions. Recombinant Uni-ZAP ${ }^{\mathrm{TM}}$ XR packaged phages were plated on Escherichia coli XL1-Blue cells. The cDNA library contained $3.6 \times 10^{6}$ recombinant plaques.

Partial cDNA inserts corresponding to PRUpe; Mdh1, PRUpe; Cs1, PRUpe; Icdh1, PRUpe; AtpvA1, PRUpe; $V p 1$ and $P R U p e ; V p 2$ were labelled with $\left[\alpha_{-}{ }^{32} \mathrm{P}\right] \mathrm{dCTP}$ using the Prime-It II Random Primer Labelling kit (Stratagene) and used as probes to screen about 300000 plaques from the cDNA library. After three rounds of screening, the positive clones were isolated and rescued from the Uni-ZAP ${ }^{\mathrm{TM}}$ XR vector using the R408 helper phage following the manufacturer's instructions 
Table 2. Characteristics of the organic acid-related full-length cDNAs isolated from peach fruit. a Suzuki et al. (1999), b percentage sequence identity determined at the amino acid level. ${ }^{\mathrm{c}}$ Location of the PCR primers used to amplify gene-specific regions. The first location given is that of the primer in the forward direction, the second (after the slash) is that of the reverse primer.

\begin{tabular}{|c|c|c|c|c|c|c|c|c|c|}
\hline \multirow[t]{2}{*}{ Protein } & \multirow[t]{2}{*}{ Gene } & \multirow[t]{2}{*}{ Type } & \multirow[t]{2}{*}{$\begin{array}{l}5^{\prime} \text {-UTR } \\
\text { (bp) }\end{array}$} & \multirow{2}{*}{$\begin{array}{l}\text { Coding } \\
\text { region } \\
\text { (bp) }\end{array}$} & \multirow{2}{*}{$\begin{array}{l}3^{\prime}- \\
\text { UTR } \\
\text { (bp) }\end{array}$} & \multicolumn{3}{|c|}{$\begin{array}{l}\text { Amino acid sequence with } \\
\text { highest identity }\end{array}$} & \multirow[t]{2}{*}{ PCR primer location } \\
\hline & & & & & & Origin & Accession & identity $^{\mathrm{b}}$ & \\
\hline $\begin{array}{l}\text { Malate } \\
\text { dehydrogenase }\end{array}$ & PRUpe;Mdh1 & cytosolic & 150 & 996 & 495 & tobacco & CAC12826.1 & $93 \%$ & 787-811/1362-1388 \\
\hline Citrate synthase & PRUpe;Cs1 & mitochondrial & 141 & 1419 & 313 & pummelo & AAA 82743.1 & $81 \%$ & $1224-1250 / 1745-1770$ \\
\hline $\begin{array}{l}\text { Isocitrate } \\
\text { dehydrogenase }\end{array}$ & PRUpe;Icdh1 & cytosolic & 150 & 1242 & 307 & celery & CAA73139.1 & $91 \%$ & $955-981 / 1460-1482$ \\
\hline $\mathrm{H}^{+}$-ATPase & PRUpe;AtpvAl & vacuolar & 136 & 1869 & 331 & $\begin{array}{l}\text { Satsuma } \\
\text { orange }\end{array}$ & BAA87891.1 & $95 \%$ & $1630-1656 / 2148-2178$ \\
\hline $\begin{array}{l}\mathrm{H}^{+} \text {-Pyro- } \\
\text { phosphatase }\end{array}$ & $\begin{array}{l}\text { PRUpe;Vp1 } \\
\text { PRUpe;Vp2 }\end{array}$ & $\begin{array}{l}\text { vacuolar } \\
\text { vacuolar }\end{array}$ & $\begin{array}{r}73 \\
117\end{array}$ & $\begin{array}{l}2301 \\
2277\end{array}$ & $\begin{array}{l}245 \\
252\end{array}$ & $\begin{array}{l}\text { pear } \\
\text { grape }\end{array}$ & aAF69010.1 & $\begin{array}{l}95 \% \\
89 \%\end{array}$ & $\begin{array}{l}2005-2032 / 2507-2533 \\
2004-2029 / 2401-2510\end{array}$ \\
\hline
\end{tabular}

(Stratagene). For each gene, the longest cDNA insert was fully sequenced.

\section{Phylogenic tree construction}

Phylogenetic trees were calculated after multiple alignment using the TREE and BOOTSTRAP option in ClustalW (http://bioweb.pasteur.fr/seqanal/interfaces/clustalw). The phylogenetic tree was constructed using the Neighbour-Joining (NJ) method (Saitou and Nei 1987). Statistical significance of a branch in the tree constructed by the NJ method was evaluated by bootstrap analysis, that is 1000 random samples of sites from the alignment, reconstructions of trees (1 from each sample) by the NJ method, and counting how many times each grouping from the original tree occurred in the sample trees.

\section{RNA blot analysis}

For each cultivar, total RNA was extracted from pooled young leaves, flower buds or fruits as indicated above. Total RNA (10 $\mu \mathrm{g}$ per lane) was denaturated $5 \mathrm{~min}$ at $70^{\circ} \mathrm{C}$ in TBE denaturing loading buffer $(2 \mathrm{X} \mathrm{TBE}$ loading buffer, 13\% (w/v) Ficoll, 0.01\% (w/v) bromophenol blue, $0.05 \%(\mathrm{w} / \mathrm{v})$ xylene cyanol, $7 \mathrm{M}$ urea), separated on a $1.2 \%(\mathrm{w} / \mathrm{v})$ agarose gel, blotted onto a Hybond-N membrane (Amersham, Les Ulis, France) and fixed by UV irradiation. Gene-specific probes were PCR-amplified at an annealing temperature of $60^{\circ} \mathrm{C}$ using forward primers designed in the $3^{\prime}$ end of the coding regions of PRUpe; Mdh1, PRUpe; CS1, PRUpe; Icdh1, PRUpe; AtpvA1, PRUpe; VP1 and PRUpe; VP2 in conjunction with reverse primers designed in the $3^{\prime}$ UTRs of these genes. Location of primers used for the amplification of each probe are given in Table2. Following hybridization with ${ }^{32} \mathrm{P}$-labelled probes at $65^{\circ} \mathrm{C}$ for $16 \mathrm{~h}$, membranes were washed twice for $20 \mathrm{~min}$ with $2 \mathrm{X} \mathrm{SSC,} 0.1 \% \mathrm{SDS}$ at $65^{\circ} \mathrm{C}$ and then twice for 20 min with $0.1 \mathrm{X} \mathrm{SSC}, 0.1 \%$ $\mathrm{SDS}$ at $65^{\circ} \mathrm{C}$. Hybridized membranes were exposed to Konica AX films between intensifying screens at $-80^{\circ} \mathrm{C}$.

Signal intensities of the autoradiographs were quantified using ImageTool software (version 2.00, University of Texas Health Science Center in San Antonio) and normalized against ethidium bromide stained rRNA.

\section{Results}

Organic acid and soluble sugar accumulation in normalacid peaches vs. low-acid peaches

Normal-acid peach Fantasia (juice titratable acidity 134 meq $1^{-1}$ and $\left.\mathrm{pH} 3.9\right)$ has round nectarine fruits, while low-acid peach Jalousia has flat peach fruits with low titratable acidity and high $\mathrm{pH}$ (juice titratable acidity 41 meq $1^{-1}$ and $\mathrm{pH} 5$ ), as determined previously at maturity (Moing et al. 2000) and throughout development (Moing et al. 1998). Fruit development and organic acid and sugar accumulations were thoroughly characterized in both cultivars to allow comparison with gene expression data. As reported previously (Moing et al. 1998, 2000), cumulative growth of Fantasia and Jalousia fruits estimated from fruit diameter follows similar patterns (Fig.

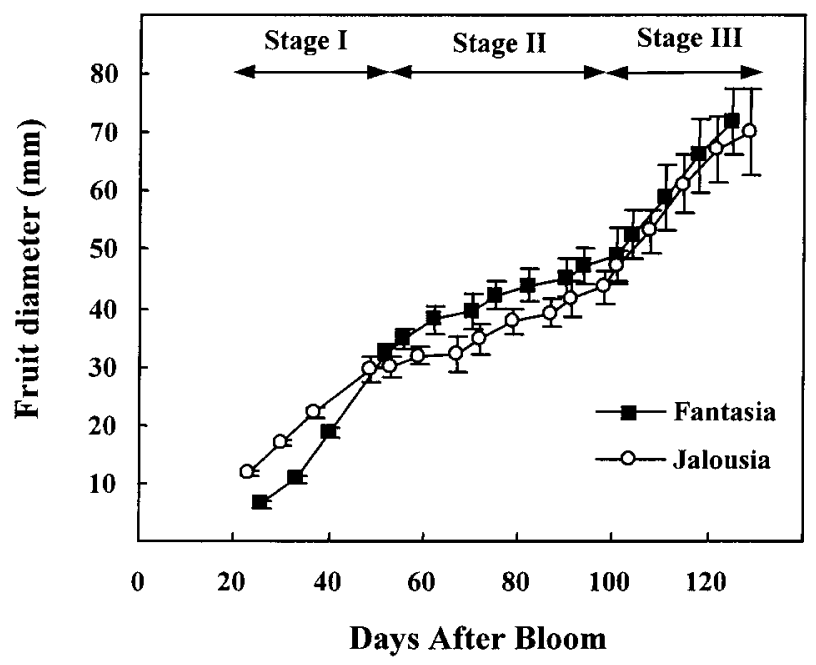

Fig. 1. Fruit growth as a function of days after bloom for Fantasia and Jalousia cultivated in a greenhouse. Fruit diameter expressed as the mean of 12 fruits per cultivar. Vertical bars represent SD. 

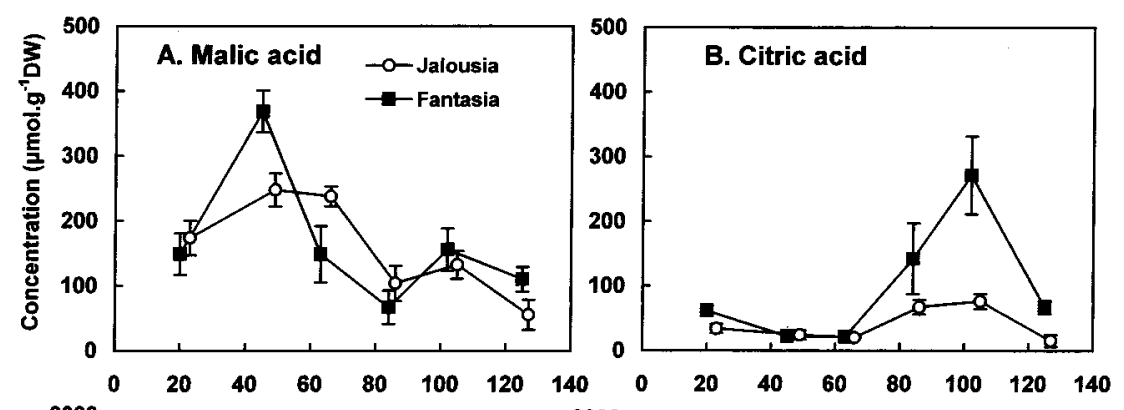

Fig. 2. Malic and citric acid, hexose and sucrose concentrations on a dry weight basis, as a function of days after bloom, in fruit mesocarp of Fantasia and Jalousia cultivated in a greenhouse. Mean of 4 fruits per cultivar. Vertical bars represent SD. (A) Malic acid (B) Citric acid (C) Glucose + fructose (D) Sucrose.

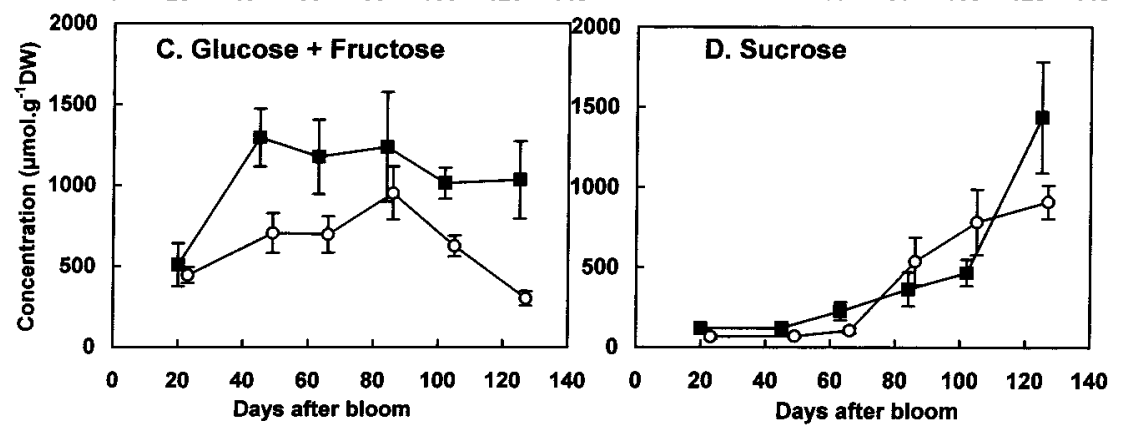

1). Transitions between growth stages I (rapid growth) and II (growth plateau) occurred at about 45-50 DAB. Transitions between growth stage II and growth stage III (rapid growth) occurred at about 100-105 DAB. Fantasia and Jalousia fruits were ripe at 124-126 DAB and 128-130 DAB, respectively. When compared to Fantasia fruit, Jalousia fruit showed a reduction in malic acid accumulation during the first rapid growth period (Fig. 2A) and a marked reduction in citric acid accumulation during the second rapid growth period (Fig. 2B). These results are consistent with those previously obtained on 3- to 4-year-old trees (Moing et al. 2000). Sugars were also affected in the low-acid genotype, since hexose content of Jalousia fruit remained significantly lower throughout fruit development (Fig. 2C), in agreement with previous results (Moing et al. 2000). The shape of the curve for sucrose accumulation and the levels of sucrose in mature fruit differed for various years (1995 data not shown, 1996 - Moing et al. 1998, 1998 - Fig. 2D). In the present study (1998), the sucrose accumulation which normally occurs during ripening was reduced in low-acid fruit.

\section{Isolation of six peach cDNAs encoding proteins involved in organic acid metabolism or storage}

Organic acid accumulation was already impaired in the low-acid genotype (Jalousia) during the first rapid growth stage, at 20-60 DAB when malic acid content peaked in normal-acid fruit (Fig. 2A). Thus, we decided to isolate genes involved in organic acid metabolism and storage which are normally expressed in Fantasia (normal-acid) fruit during the first rapid growth stage (45 DAB), with the aim of determining their expression pattern in normal-acid and low-acid fruits. We accordingly designed sets of three degenerate primers for conserved protein domains found in cytosolic NAD-dependent malate dehydrogenase (NAD-MDH), mitochondrial citrate synthase (CS), the catalytic subunit A of vacuolar $\mathrm{H}^{+}$-ATPase (V-ATPase) and vacuolar $\mathrm{H}^{+}$-pyrophosphatase (V-PPase), and a set of two primers for cytosolic NADP-dependent isocitrate dehydrogenase (NADP$\mathrm{ICDH})$. Partial cDNAs encoding these proteins were successfully isolated from peach fruit by RT-PCR. After a first round of PCR amplification with forward and reverse degenerate primers (F1 and R; Table 1), the PCR product was used as a template for a second round of PCR amplification using a nested forward primer and the reverse primer (F2 and R; Table 1), when necessary, in order to increase the specificity of cDNA amplification (see Materials and methods). Primers designed for cytosolic aconitase and NADP-dependent malic enzyme failed to amplify any cDNA at this stage of peach fruit development.

Screening of a peach fruit cDNA library constructed from $30 \mathrm{DAB}$ fruit using the PCR fragments as probes allowed the successful isolation of full-length clones for each of the cDNAs previously isolated by RT-PCR. However, in the case of cytosolic NADP-ICDH, library screening yielded only one full-length cDNA, which corresponded to the more abundant of the two cDNAs isolated from peach fruit by RT-PCR. In contrast, two different full-length clones of V-PPase were isolated from peach fruit.

\section{Characterization of the organic acid-related cDNAs isolated from peach fruit}

Characteristics of the full-length cDNA clones isolated are presented in Table2. Comparison of the deduced amino-acid sequences with the corresponding plant protein sequences available in databases enabled the unequi- 
vocal identification of full-length cDNA clones encoding cytosolic NAD-MDH (PRUpe;Mdh1), mitochondrial CS (PRUpe;Cs1), cytosolic NADP-ICDH (PRUpe;$I c d h 1)$, the catalytic subunit A of V-ATPase (PRUpe;AtpvA1) (Ratajczak 2000) and V-PPase (PRUpe; Vpl and PRUpe;Vp2) (Maeshima 2000).

PRUpe;Mdh1 product (PPMDH1) shared at least $90 \%$ identity at the amino-acid level with plant cytosolic NAD-MDH present in sequence databases and was found to be clustered with dicotyledon cytosolic NADMDH (bootstrap value: 99.8, data not shown). PRUpe; CS1 product (PPCS1) shared about $80 \%$ identity with plant mitochondrial CS sequences previously reported, with the exception of Arabidopsis thaliana CS [69\% identity; GenBank accession number CAA35570.1 (Unger et al. 1989)], and exhibited its highest identity (81\%) with the pummelo mitochondrial CS isolated from juice sac cells [(Canel et al. 1996), GenBank accession number AAA82743.1]. Furthermore, both proteins were shown to be paired in a phylogenetic tree constructed after alignment of protein sequences from plant CS (bootstrap value 67; data not shown). PRUpe;Icdh1 product (PPICDH1) showed about 90\% identity with putative plant cytosolic proteins, among which is the cytosolic lemon NADP-ICDH expressed in juice sac cells (Sadka et al. 2000a). Peach V-ATPase PRUpe;AtpvAl product (PPVATP-A1) shared 95\% identity with most of the plant V-ATPase catalytic subunit A proteins, among which is the deduced amino acid sequence from the fulllength cDNA isolated from juice sac cells of Satsuma orange (Citrus unshiu) (Takanokura et al. 1998). In the phylogenetic tree of V-ATPases (Fig. 3A), PPVATP-A1 fell into a cluster which grouped the majority of dicotyledon V-ATPases (bootstrap value: 52) including fruit VATPase from pummelo (bootstrap value: 39). Peach VPPases PRUpe;Vp1 and PRUpe;Vp2 products (PPVP1 and PPVP2) shared $82 \%$ identity, and $80-95 \%$ identity with other plant V-PPases. In the phylogenetic tree of VPPases (Fig. 3B), PPVP1 fell into a cluster which grouped the majority of plant V-PPases and was paired with the V-PPase isolated from mature pear (Pyrus communis) fruits (Suzuki et al. 1999) (bootstap value: 100). Most interestingly, PPVP2 was paired in a different cluster with the V-PPases isolated from grape (Vitis vinifera) berry at the veraison stage (GenBank accession number AAF69010.1, bootstrap value: 100).

\section{Differential expression of organic acid-related genes in low-acid vs. normal-acid peaches}

Gene-specific probes consisting of 133-389 bp of the $3^{\prime}-$ UTR and 211-396 bp of the coding region of the genes (Table2) were PCR-amplified from the cDNAs isolated by library screening. We further verified that no cross-hybridization occurred between PRUpe; $V p 1$ and $P R U p e ; V p 2$ (data not shown). The probes were used in northern blot analyses with total RNA extracted from normal-acid and low-acid peach fruit (mesocarp plus epidermis). Expression patterns were determined throughout fruit development, at stages representative of cell division (20 DAB and 23 DAB for Fantasia and Jalousia, respectively), first rapid growth stage (45-49 DAB), growth plateau (63-66 DAB and 84-86 DAB), second rapid growth stage (102-105 DAB) and ripening (125-127 DAB). To investigate whether the expression of the 6 genes previously isolated was fruit-specific, flower buds and young leaves were also included in the analysis.

As shown in Fig. 4, all the genes were expressed in young leaves, flower buds and fruits of both cultivars. The expression of V-PPase PRUpe;Vp2 was much stronger in fruit than in young leaves or flower buds. The level of transcripts for PRUpe;Mdh1, PRUpe;Icdh1, PRUpe;AtpvAl and PRUpe; Vpl were similar in young leaves and flower buds and during the earlier developmental stages of the fruit, from about 20-65 DAB (Fig. 4) while mitochondrial CS, $P R U p e ; C s 1$, exhibited a very strong expression in flower buds and low expression in fruit from 20 to $65 \mathrm{DAB}$. This last result is consistent with the high level of expression of mitochondrial CS observed previously in anthers of developing flowers of potato (Landschutze et al. 1995).

For all the genes studied, the level of transcripts was developmentally regulated in peach fruit (Figs 4 and 5). Considering the expression patterns for normal-acid fruit (Figs 4 and 5 Fantasia), the steady-state transcript levels of PRUpe;Mdh1 (Fig. 5A) increased slowly 60 DAB to maturity while that of PRUpe; CS1 (Fig. 5B) or PRUpe;Icdh1 (Fig. 5C) showed preferential expression in the later stages of fruit development with a stronger transcript accumulation in ripe fruit (125-127 DAB). The expressions of the genes encoding proton pumps also varied (Figs 4 and 5D,E,F). Probes for PRUpe;AtpvA1, PRUpe;Vp1 and PRUpe;Vp2 labelled to the same specific activities enabled direct comparisons of the transcript abundance for each gene. PRUpe; $V p 1$, one of the two genes encoding V-PPase isolated from developing peach fruit, was expressed at a low level throughout peach fruit development. More interestingly, PRUpe;AtpvA1 and PRUpe; Vp2 showed a biphasic pattern of transcript accumulation (Fig.4). For PRUpe;AtpvA1, the first expression peak (45 DAB) was concomitant with malic acid accumulation (Fig. 2A) and the second expression peak (102-125 DAB) corresponded to citric acid peak (Fig. 2B) and maturity. For PRUpe;Vp2 the first expression peak (45 DAB) was concomitant with malic acid accumulation (Fig. 2A,B) and the second expression peak corresponded to maturity.

The expression patterns for organic acid-related genes are strikingly similar between the normal-acid (Fantasia) and the low-acid fruit (Jalousia) (Figs 4 and 5). This allows confirmation of preferential expression for organic acid-related genes in ripe fruit. However, $P R U p$ $e ; M d h 1$ tended to be more highly expressed in the normal-acid fruit (Fantasia) than in the low-acid fruit (Jalousia) from $80 \mathrm{DAB}$ to maturity. Moreover, proton pumps AtpvA1 during cell division, and PRUpe; Vp2 at citric acid peak and at maturity, were more highly ex- 
A

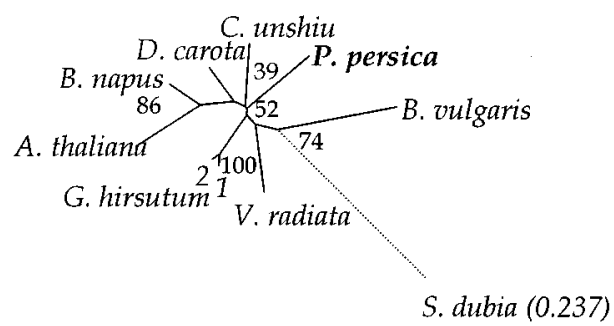

B

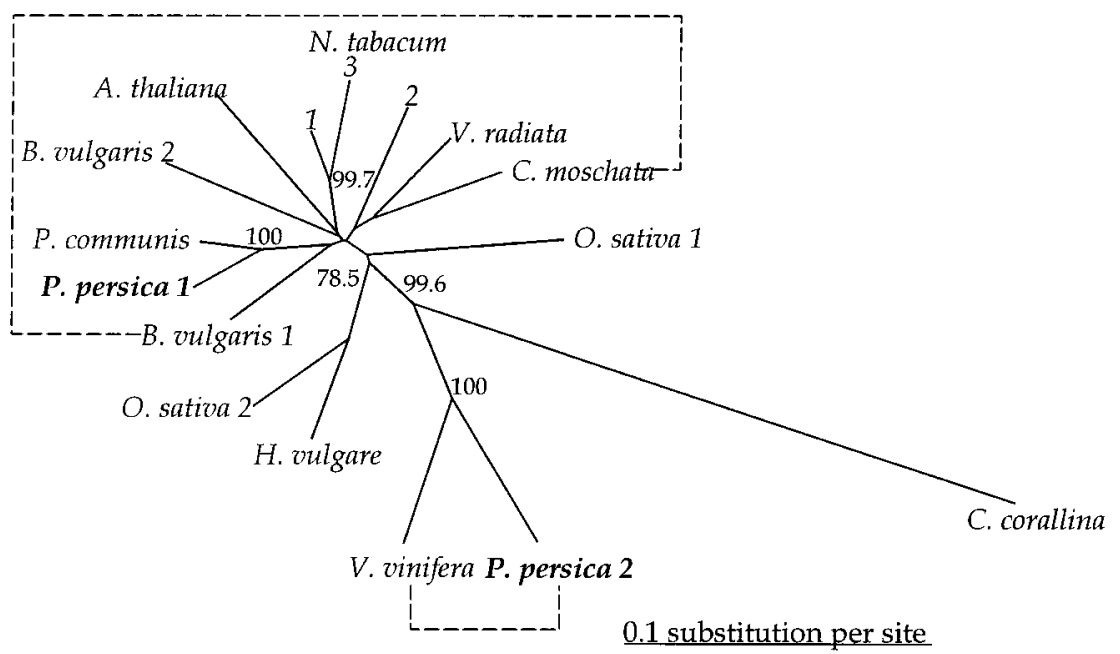

Fig. 3. Phylogenetic analysis of peach VATPase (PPVATP-A1: P. persica) (Fig. 3A), and of the two peach V-PPases (PPVP1: $P$. persica 1, PPVP2: P. persica 2) (Fig. 3B) with the other plant homologous putative proteins, selected from optimal amino acid alignment of complete sequences. The length of lines is proportional to the genetic distances between each node. The unit is the number of substitutions per site. The integer indicates the statistical significance of the branch, that is, the percentage of appearances of the branch in one thousand bootstrap samplings and tree reconstructions. Only percentages greater than 50 are indicated. In Fig. 3B the dotted lines delimit the dicotyledon groups. The sequences shown for VATPase are from Arabidopsis thaliana (GenBank accession number AAB97128.1), Brassica napus (AAA82881.1), Beta vulgaris (CAA67305.1), Citrus unshiu (BAA87891.1), Daucus carota (AAA33139.1), Gossypium hirsutum (AAC17840.1 and AAA33050.1), Scherffelia dubia (CAB55557.1) and Vigna radiata (AAC49174.1). The sequences for V-PPase are from Arabidopsis thaliana (GenBank accession number AAA32754.1), Beta vulgaris (BVP1 and BVP2; AAA61609.1 and AAA61610.1), Chara corallina (BAA36841.1), Cucurbita moschata (BAA33149.1), Hordeum vulgare (BAA02717.2), Nicotiana tabacum (CAA58701.1, CAA58700.1 and CAA58699.1), Oryza sativa (OVP1 and OVP2; BAA31523.1 and BAA31524.1), Vigna radiata (AAC49175.1), Vitis vinifera (AAF69010.1). The Pyrus communis amino acid sequence was introduced from Suzuki et al. (1999). pressed in the low-acid fruit (Jalousia). PRUpe:Vp1 also tended to be more highly expressed in the low-acid fruit (Jalousia) at citric acid peak and maturity.

\section{Discussion}

Like most other edible fleshy fruits (Monselise 1986, Tucker 1993), peach fruit is acid with ripe fruit juice $\mathrm{pH}$ of 3.0-4.0 and juice titratable acidity from 80 to 200 $\mathrm{mEq}^{-1}$ (Dirlewanger et al. 1999). Although other fruits such as grape and lemon fruits exhibit even lower juice $\mathrm{pH}$ during fruit development [pH 2.5 (Müller et al. 1996, Terrier et al. 1998)], the cells of peach fruit mesocarp are nevertheless considerably more acid than most plant cells which usually have vacuolar $\mathrm{pHs}$ close to 5-5.5 (Maeshima et al. 1996). Peach fruit acidity results from the synthesis and accumulation of the major organic acids, malic and citric acids. This occurs during the earlier stages of fruit development, from the end of the cell division stage to the onset of ripening (Fig. 2A,B). The increase in malic acid (20-40 DAB) is concomitant with the first rapid growth stage of peach fruit, while the increase in citric acid (80-100 DAB) is concomitant with the beginning of the second rapid growth stage (Figs $1,2)$. Both rapid growth stages are associated with the enlargement of mesocarp cells where organic acids are stored (Masia et al. 1992). Later, during ripening, the concentration of organic acids (on a DW basis) decreases due to reduced synthesis/enhanced catabolism of organic acids (Tucker 1993), and to massive import and accumulation of sugars from phloem at that stage of fruit development (DW dilution effect, Fig. 2C,D). Thus, fruit offers a unique model to study the regulation of processes related to metabolism and storage of organic acids in plant.

\section{Genes involved in organic acid synthesis and storage are differentially regulated during peach fruit development}

Since fruit undergoes a continuous accumulation of organic acids over a long period of development, which lasts for about $80 \mathrm{~d}$ in peach (Figs 1 and $2 \mathrm{~A}, \mathrm{~B}$ ) and up to $200 \mathrm{~d}$ in some fleshy fruit species (Monselise 1986), fruit-specific genes may have evolved in order to allow 
Fantasia

$\begin{array}{llllllll}\text { YL FB } & 20 & 45 & 63 & 84 & 102 & 125\end{array}$


rRNA

PRUpe;IcdhI
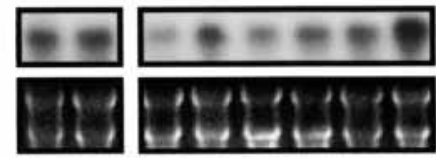

PRUpe;AtpvAI

rRNA
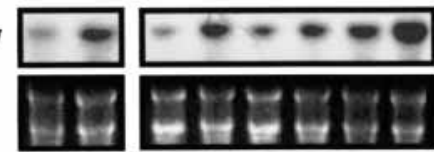

PRUpe;Vp1

$r R N A$
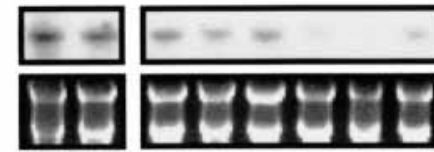

PRUpe;Vp2


Jalousia

$\begin{array}{llllllll}\text { YL } & \text { FB } & 23 & 49 & 66 & 86 & 105 & 127\end{array}$
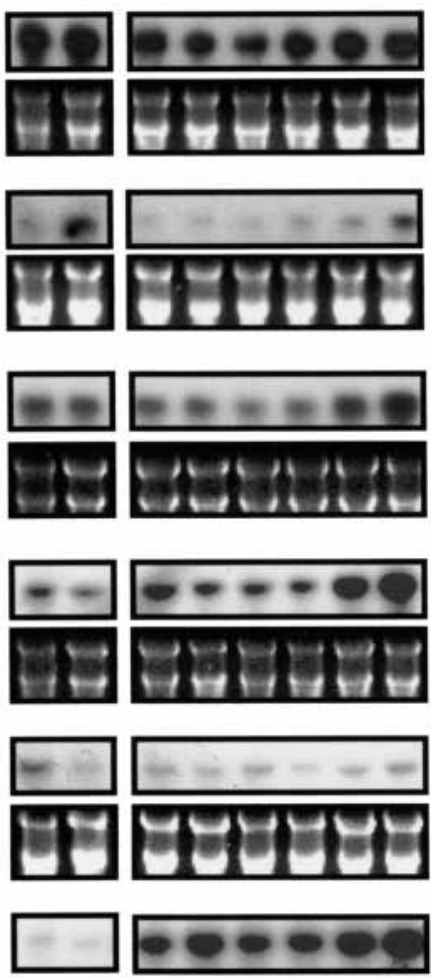

19.9
Fig. 4. Expression analyses of the six cDNAs isolated from peach fruit at the indicated stages of fruit development (DAB), peach young leaves (YL), and flower buds (FB) in Fantasia and Jalousia cultivated in a greenhouse. Northern blots were probed with ${ }^{32} \mathrm{P}$-labelled $3^{\prime}$ specific cDNA fragments for cytosolic NADdependent malate dehydrogenase PRUpe;Mdh1, mitochondrial citrate synthase PRUpe;CS1, cytsosolic NADPdependent isocitrate dehydrogenase PRUpe;Icdh1, V-ATPase catalytic subunit A PRUpe;AtpvAl and V-PPases $P R U p e ; V p 1$ and $P R U p e ; V p 2$. tight control of organic acid metabolism and storage in this specialized organ. In the present study, the isolation of six new peach genes encoding proteins involved in malic acid synthesis and degradation (cytosolic NAD$\mathrm{MDH}$ ), citric acid synthesis and degradation (mitochondrial CS and cytosolic NADP-ICDH) and vacuolar storage of organic acids (V-ATPase subunit A and V-PPase) (Table 2) enabled us to undertake a study of their expression in the fruit, in relation with organic acid and sugar accumulations (Fig. 2).

Sequence comparisons (Table 2) and phylogenetic analyses (Fig. 3A,B) indicate that five of these peach genes involved in organic acid accumulation are homologous to genes isolated from fruit in other fleshy fruit species: pummelo and lemon (PRUpe; Csl, and PRUpe;AtpvA1), pear (PRUpe;Vp1) and grape (PRUpe;Vp2). $P R U p e ; M d h 1$ has no known fruit homologue and thus represents, to the best of our knowledge, the first cytosolic malate dehydrogenase gene isolated from fruit. Figure 4 shows that all genes studied were not only expressed in fruit but also in young leaves and flower buds, and therefore do not display a fruit-specific expression. Thus organic acid accumulation in fruit differs from some other well-known fruit developmental processes such as ripening-associated ethylene synthesis and cell wall degradation which involve highly expressed fruitspecific genes (Callahan et al. 1993).

Although not specifically expressed in the fruit, we expected that the genes involved in organic acid synthesis, degradation or storage would show a differential expression during fruit development. A previous study indicated that PEPC might be involved in the control of organic acid content during the development of normalacid Fantasia fruit (Moing et al. 2000). In the present study, most genes studied show a stronger expression in ripening fruit than during the earlier phases of development. However, their expression patterns do not necessarily correlate with the timing of the changes in organic acid contents although both analyses (Northern blot and organic acid measurements) were carried out on the same fruits. The steady state transcript abundance of CS, which controls a step in citric acid synthesis, peaked in normal-acid Fantasia fruit at about 120 DAB, i.e. 20 days after the peak of citric acid (Fig. 2A). Similarly, the citric acid level was not correlated with citrate synthase expression in Citrus (pummelo) fruit (Canel et al. 1996). The next step in the citric acid cycle is catalysed by ACO, which converts citrate to isocitrate. We did not succeed in the isolation of cytosolic ACO gene (the only plant aconitase gene cloned to date) from early developing 

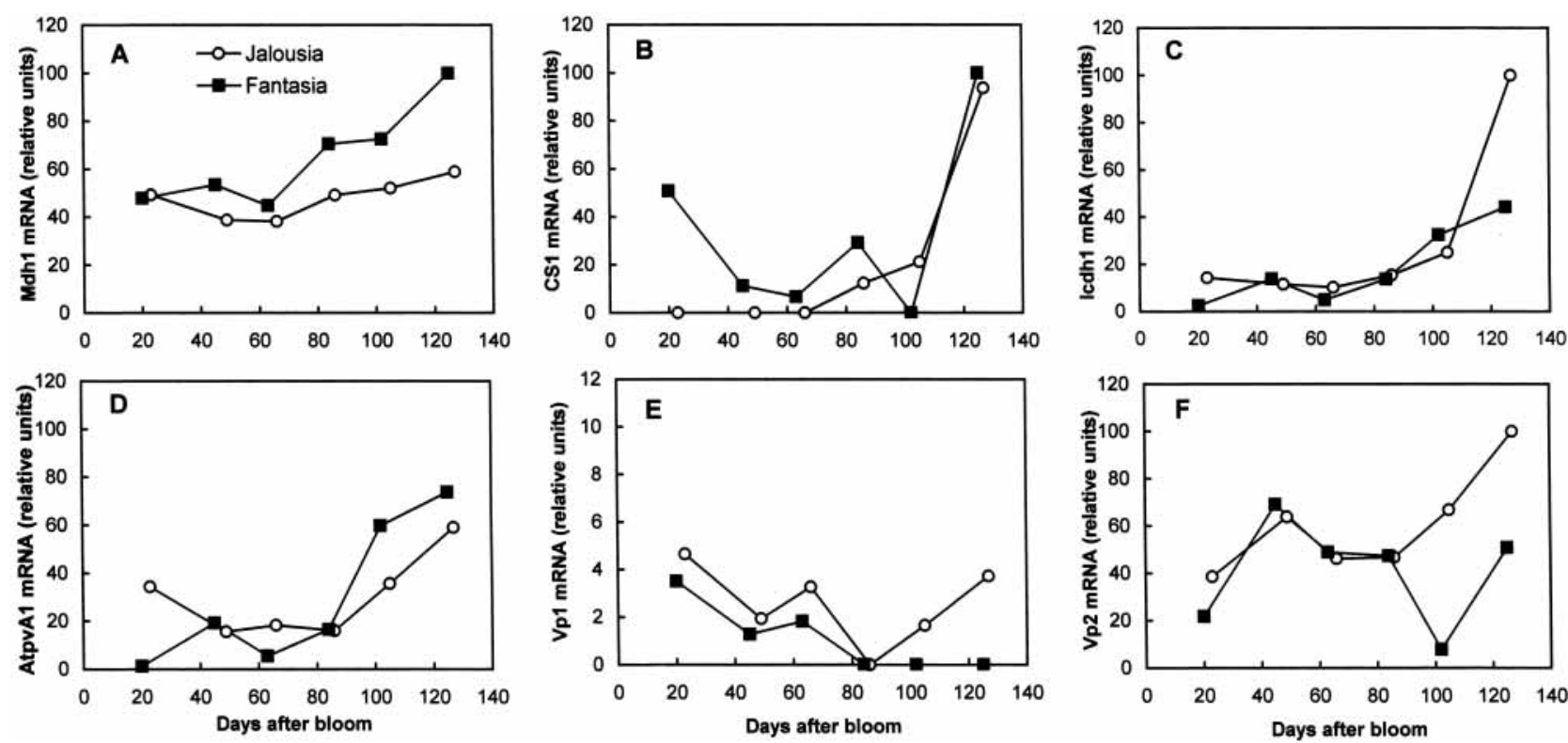

Fig. 5. Expression analyses of the six cDNAs isolated from peach fruit at the indicated stages of fruit development (Days after bloom) in Fantasia and Jalousia fruits cultivated in a greenhouse. Densitometrical analysis of mRNA levels from Fig. 4, normalized against rRNA and plotted as a percentage of the maximum level of each normalized mRNA for Mdh1, CS1 and Icdh1, and as a percentage of the maximum level of Vp2 for AtpvA1, Vp1 and Vp2. (A) cytosolic NAD-dependent malate dehydrogenase PRUpe;Mdh1; (B) mitochondrial citrate synthase PRUpe;CS1; (C) cytsosolic NADP-dependent isocitrate dehydrogenase PRUpe;Icdh1; (D) V-ATPase catalytic subunit A PRUpe;AtpvA1; (E) V-PPase PRUpe;Vp1 and (F) V-PPase PRUpe;Vp2.

peach fruit, although this enzyme is constitutively expressed at the RNA level in lemon fruit pulp (Sadka et al. 2000b). Recently, Sadka et al. 2000b, proposed a model attributing the increase in citrate concentration in sour lemon fruit to a reduction in mitochondrial aconitase activity. Although this mechanism may also be operative in peach, additional factors are probably needed in order to allow the accumulation of both malic and citric acids in this fruit. Isocitrate is converted to 2-oxoglutarate by ICDH. NADP-ICDHs are found in different cellular compartments (Galvez et al. 1999). As in most other fruits (Monselise 1986), the peak of expression of cytosolic PRUpe;Icdh1 in late stages of fruit development (Fig. 4) is consistent with an increased catabolism of organic acids resulting in the decrease in organic acid content observed in peach (Fig. 2A,B). ICDH activity has been reported to increase during development of sour lemon (Sadka et al. 2000a) and tomato (Gallardo et al. 1995) fruit, together with transcript levels of cytosolic ICDH in sour lemon fruit (Sadka et al. 2000a). It has been suggested that NADP-ICDH might be involved in the catabolism of citric acid for glutamate formation in ripe tomato (Gallardo et al. 1995), though this is probably not the case in peach fruit which does not accumulate glutamate (Moing et al. 1998). One of the reasons which probably accounts for the discrepancies observed between organic acid levels and expressions of genes involved in organic acid metabolism in the fruit is post-transcriptional and post-translational regulation of these genes (MacKintosh 1998). An alternative expla- nation is that we carried out these analyses on whole fruit (mesocarp plus epidermis) while organic acid-related enzymes present distinct spatial expressions throughout fruit development as recently shown in grape (Famiani et al. 2000).

Organic acid storage in the vacuole is dependent upon a proton gradient established by the two tonoplastic proton pumps, V-ATPase and V-PPase, that provides the driving force for their transport (Müller et al. 1996, Martinoia and Ratajczak 1998). Transcript abundance of V-ATPase PRUpe; AtpvAl in Fantasia fruit was similar to that of V-PPase PRUpe; $V p 2$ (the two probes were labelled to the same specific activity) and peaked towards stage I (first growth stage, Fig. 1) and ripening (Figs 4 and 5). This result is in agreement with expression studies carried out on Citrus unshiu fruit where transcripts corresponding to a cDNA with high similarity to PRUpe;AtpvA1 (87\% identity at the nucleotidic level) accumulated during early fruit development and during ripening (Takanokura et al. 1998). The use of gene-specific probes enabled us to distinguish between two pyrophosphatase genes: PRUpe; VP1 showing low expression in fruit, and PRUpe; Vp2 showing high expression in fruit. $P R U p e ; V p 2$ showed a clear biphasic pattern of expression during peach fruit development (Figs 4 and 5) which was correlated with the accumulation of malic or citric acids from 45 to 84 DAB (Fig. 2A,B), and with maturation. Suzuki et al. (1999) isolated from fruit of European pear, another Rosaceous species, a full-length cDNA highly similar to PRUp- 
$e ; \operatorname{Vpl}(91 \%$ identity at the nucleotidic level) which appeared to be actively transcribed towards maturation. In the same study, a strong signal was detected for V-PPase protein in young fruit using antibodies against mung bean V-PPase (Suzuki et al. 1999). In contrast, changes in the levels of transcript, protein and activity of V-PPase of Japanese pear peaked in late stages of fruit development and were all correlated (Suzuki et al. 2000). It should be noted that in contrast to these studies, the probe used in the present work permitted the specific detection of PRUpe; $V p 1$ and PRUpe; Vp2. Based on biochemical studies of V-ATPase from the very acidic lemon fruit, it was proposed that a particular isoform of VATPase with distinct functional properties allows the hyperacidification in Citrus (Müller et al. 1996, 1997). The strong expression in peach fruit of one of the other two tonoplastic $\mathrm{H}^{+}$-pumps expressed in the fruit, the V-PPase PRUpe; Vp2, suggests that peach fruit possesses in addition a V-PPase involved in the establishment of a proton gradient across the tonoplast for organic acid, and possibly, sugar storage (Echeverria et al. 1997). Isolation and biochemical characterization of additional fruit pyrophosphatases would, however, be necessary to confirm the existence in fleshy fruits of a specialized VPPase isoform. According to studies of grape berry proton pumps, a V-PPase highly similar to PRUpe; Vp2 (Fig. 3) has been shown to be highly expressed during ripening and to have a synergistic behaviour with V-ATPase (Terrier et al. 2001).

\section{Are any of the organic acid-related genes isolated involved in the differences of acidity between normal-acid and low-acid cultivars?}

In the low-acid peach cultivar Jalousia, which exhibits higher $\mathrm{pH}(5)$ and lower titratable acidity $\left(41 \mathrm{mEq}^{-1}\right)$ than the normal-acid fruit $\left(\mathrm{pH} 3.9\right.$ and $\left.134 \mathrm{mEq}^{-1}\right)$ (Moing et al. 1998), the accumulation of hexoses and both malic and citric acids is reduced throughout fruit development (Fig. 2A,B,C). The reduction in glucose and fructose accumulation in Jalousia, as compared to Fantasia might result from a lower rate of sugar phloem transport or unloading which could in turn reduce the glycolitic carbon flow from carbohydrates to organic acids, and therefore reduce organic acid concentration. However, this hypothesis remains to be tested. We previously provided evidence that PEPC does not account for the phenotypic difference observed between Fantasia and Jalousia fruit (Moing et al. 1999, 2000). Here, we further show that no clear-cut difference between normal-acid and low-acid fruit exists at the level of gene expression for six genes involved in organic acid synthesis, degradation or storage (Figs 4 and 5). It should, however, be stressed that this result does not exclude possible changes at the level of protein expression or protein functionality in the low-acid genotype. The only genes which show a modification of their expression in the low-acid fruit compared to the normal-acid fruit are the tonoplastic proton pumps PRUpe;AtpvAl, PRUp$e ; V P 2$, and to a lesser extent $P R U p e ; V p 1$. Surprisingly, V-ATPase PRUpe;AtpvAl was more highly expressed in the low-acid genotype than in the normal-acid genotype during cell division phase, and V-PPase PRUpe;VP2 appeared to be more highly expressed in the low-acid genotype than in the normal-acid genotype at a critical stage of citric acid accumulation (Figs 4 and 5). This result would be consistent with the hypothesis of an increased leakage of the vacuole in the low-acid fruit, leading to an increased expression of vacuolar proton pumps to partially compensate for proton leakage (Echeverria et al. 1997). However, measurements of expression at the protein level and of activities of the proton pumps are necessary to confirm this hypothesis. In grape, a decrease in tonoplast tightness leading to deacidification during ripening was proposed (Terrier et al. 2000). Increased proton leakage out of the vacuole would explain the lower accumulation of organic acids in the peach fruit (Martinoia and Ratajczak 1998), and, possibly, the reduced accumulation of sugars (Fig. 2). Indeed, according to Echeverria et al. (1997), to move into the vacuole, sugars might also depend on a proton gradient, although this hypothesis is not widely accepted (Martinoia and Ratajczak 1998). Mapping of the genes that we isolated vs. quantitative trait loci (QTLs) controlling organic acid and sugar contents in an offspring issued from a Jalousia $\times$ Fantasia cross (Dirlewanger et al. 1999), are underway and should provide additional evidence for the involvement of these genes in the control of organic acids and sugar contents in the low-acid peach fruit.

Accession numbers: PRUpe; $M d h 1, \mathrm{AF} 367442 ; P R U$ pe;Cs1, AF367444; PRUpe;Icdh1, AF367443; PRUpe;AtpvA1, AF367445; PRUpe;Vp1, AF367446; PRUpe; $V p 2$, AF367447.

Acknowledgements - We thank Alain Bonnet for taking care of the peach trees, Laurence Svanella-Dumas for metabolite analyses, Agnès Destrac-Irvine for cloning and sequencing of partial cDNAs, Drs D. Just, C. Chevalier and F. Laigret for critical reading of the manuscript and B. Ricard for language corrections. This work was partly funded by grants from the Institut National de la Recherche Agronomique, France (A.I.P. Génome des Plantes Cultivées and A.I.P. AGRAF), and from Région Aquitaine (Project 98 0307005).

\section{References}

Barbier-Brygoo H, Vinauger M, Colcombet J, Ephritikhine G, Frachisse JM, Maurel C (2000) Anion channels in higher plants: functional characterization, molecular structure and physiological role. Biochim Biophys Acta 1465: 199-218

Barkla BJ, Pantoja O (1996) Physiology of ion transport across the tonoplast of higher plants. Ann Rev Plant Physiol Plant Mol Biol 47: 159-184

Boubals D, Bourzeix M, Guitraud J (1971) Le Gora Chirine, variété de vigne iranienne à faible teneur en acides organiques. Ann Amélior Plantes 21: 281-285

Callahan AM, Morgens PH, Cohen RA (1993) Isolation and initial 
characterization of cDNAs for messenger RNAs regulated during peach fruit development. J Am Soc Hortic Sci 118: 531-537

Cameron JW, Soost RK (1977) Acidity and total soluble solids in Citrus hybrids and advanced crosses involving acidless orange and acidless pummelo. J Am Soc Hort Sci 120: 510-514

Canel C, Bailey-Serres JN, Roose ML (1995) In vitro $\left[{ }^{14} \mathrm{C}\right]$ citrate uptake by tonoplast vesicles of acidless Citrus juice cells. J Am Soc Hortic Sci 120: 510-514

Canel C, Bailey-Serres JN, Roose ML (1996) Molecular characterization of the mitochondrial citrate synthase gene of an acidless pummelo (Citrus maxima). Plant Mol Biol 31: 143-147

Chollet R, Vidal J, O'Leary MH (1996) Phosphoenolpyruvate carboxylase: a ubiquitous, highly regulated enzyme in plants. Annu Rev Plant Physiol Plant Mol Biol 47: 273-298

Diakou P, Svanella L, Raymond P, Gaudillere JP, Moing A (2000) Phosphoenolpyruvate carboxylase during grape berry development: protein level, enzyme activity and regulation. Aust J Plant Physiol 27: 221-229

Dirlewanger E, Moing A, Rothan C, Svanella L, Pronier V, Guye A, Plomion C, Monet R (1999) Mapping QTLs controlling fruit quality in peach (Prunus persica (L.) Batsch). Theor Appl Genet 98: $18-31$

Echeverria E, Gonzalez PC, Brune A (1997) Characterization of proton and sugar transport at the tonoplast of sweet lime (Citrus limmetioides) juice cells. Physiol Plant 101: 291-300

Famiani F, Walker RP, Tecsi L, Chen ZH, Proietti P, Leegood RC (2000) An immunohistochemical study of the compartmentation of metabolism during the development of grape (Vitis vinifera L.) berries. J Exp Bot 51: 675-683

Fang DQ, Federici CT, Roose ML (1997) Development of molecular markers linked to a gene controlling fruit acidity in citrus. Genome 40: 841-849

Fulton TM, Grandillo S, BeckBunn T, Fridman E, Frampton A, Lopez J, Petiard V, Uhlig J, Zamir D, Tanksley SD (2000) Advanced backcross QTL analysis of a Lycopersicon esculentum $\mathrm{x}$ Lycopersicon parviflorum cross. Theor Appl Genet 100: 10251042

Gallardo F, Galvez S, Gadal P, Canovas GM (1995) Changes in $\mathrm{NADP}^{+}$-linked isocitrate dehydrogenase during tomato fruit ripening. Characterization of the predominant cytosolic enzyme from green and ripe pericarp. Planta 196: 148-154

Galvez S, Lacian M, Hodges M (1999) Are isocitrate dehydrogenases and 2-oxoglutarate involved in the regulation of glutamate synthesis? Trends Plant Sci 4: 484-490

Landschutze V, Muller-Rober B, Willmitzer L (1995) Mitochondrial citrate synthase from potato: predominant expression in mature leaves and young flower buds. Planta 196: 756-764

MacKintosh C (1998) Regulation of cytosolic enzymes in primary metabolism by reversible protein phosphorylation. Curr Opin Plant Biol 1, 224-229

Maeshima M (2000) Vacuolar $\mathrm{H}^{+}$-pyrophosphatase. Biochim Biophys Acta 1465: 37-51

Maeshima M, Nakanishi Y, Matsuuraendo C, Tanaka Y (1996) Proton pumps of the vacuolar membrane in growing plant cells. J Plant Res 109: 119-125

Maliepaard C, Alston FH, Arkel GV, Brown LM, Chevreau E, Dunemann F, Evans KM, Gardiner S, Guilford P, Heusden AWV Janse J, Laurens F, Lynn JR, Manganaris AG, Nijs APM, d Periam N, Rikkerink E, Roche P, Ryder C, Sansavini S, Schmid H, Tartarini S, Verhaegh JJ, Vrielink-van Ginkel M, King GJ (1998) Aligning male and female linkage maps of apple (Malus pumila Mill.) using multi-allelic markers. Theor Appl Genet 97: $60-73$

Martinoia E, Ratajczak R (1998) Transport of organic molecules across the tonoplast. In: Leigh RA, Sanders D (eds) The Plant Vacuole. Academic Press, London, pp 365-400

Masia A, Zanchin A, Rascio N, Ramina A (1992) Some biochemical and ultrastructural aspects of peach fruit development. J Am Soc Hortic Sci 117: 808-815

Miller SS, Driscoll BT, Gregerson RG, Gantt JS, Vance CP (1998) Alfalfa malate dehydrogenase (MDH): molecular cloning and characterization of five different forms reveals a unique noduleenhanced MDH. Plant J 15: 173-184

Moing A, Rothan C, Svanella L, Just D, Diakou P, Raymond P, Gaudillere JP, Monet R (2000) Role of phosphoenolpyruvate carboxylase in organic acid accumulation during peach fruit development. Physiol Plant 108: 1-10
Moing A, Svanella L, Gaudillere M, Gaudillere JP, Monet R (1999) Organic acid concentration is little controlled by phosphoenolpyruvate carboxylase activity in peach fruit. Aust J Plant Physiol 26: $579-585$

Moing A, Svanella L, Rolin D, Gaudillere M, Gaudillere JP, Monet $\mathrm{R}$ (1998) Compositional changes during the fruit development of two peach cultivars differing in juice acidity. J Am Soc Hortic Sci 123: $770-775$

Monet R (1979) Transmission génétique du caractère 'fruit doux' Chez le pêcher. Incidence sur la sélection pour la qualité. Eucarpia fruit section. Tree Fruit Breeding, Angers, France, INRA, Angers.

Monselise SP (1986) Closing remarks. In: Monselise SP, ed. CRC Handbook of Fruit Set and Development, CRC Press, Boca Raton, FL, pp. 521-537

Müller ML, Irkens-Kiesecker U, Kramer D, Taiz L (1997) Purification and reconstitution of the vacuolar $\mathrm{H}^{+}$-ATPases from lemon fruits and epicotyls. J Biol Chem 272: 12762-12770

Müller ML, Irkens-Kiesecker U, Rubinstein B, Taiz L (1996) On the mechanism of hyperacidification in lemon. J Biol Chem 271: 1916-1924

Oleski N, Mahdavi P, Peiser G, Bennett AB (1987) Transport properties of the tomato fruit tonoplast. I. Identification and characterization of an anion-sensitive $\mathrm{H}^{+}$-ATPase. Plant Physiol 84: 993-996

Or E, Baybik J, Sadka A, Saks Y (2000) Isolation of mitochondrial malate dehydrogenase and phosphoenolpyruvate carboxylase cDNA clones from grape berries and analysis of their expression pattern throughout berry development. J Plant Physiol 157: $527-534$

Popova TN, Pinheiro de Carvalho MAA (1998) Citrate and isocitrate in plant metabolism. Biochem Biophys Acta 1364: 307325

Ratajczak R (2000) Structure, function and regulation of the plant vacuolar $\mathrm{H}^{+}$-translocating ATPase. Biochim Biophys Acta 1465: $17-36$

Ruffner HP (1982) Metabolism of tartaric and malic acids in Vitis: a review - Part B. Vitis 21: 346-358

Sadka A, Dahan E, Or E, Cohen L (2000a) NADP ${ }^{+}$-isocitrate dehydrogenase gene expression and isozyme activity during citrus fruit development. Plant Sci 158: 173-181

Sadka A, Dahan E, Cohen L, Marsh KB (2000b) Aconitase activity and expression during the development of lemon fruit. Physiol Plant 108: 255-262

Saitou N, Nei M (1987) The neighbor-joining method: a new method for reconstructing phylogenetic trees. Mol Biol Evol 4: 406-425

Saliba-Colombani V, Causse M, Langlois D, Philouze J, Buret M (2001) Genetic analysis of organoleptic quality in fresh market tomato. 1. Mapping QT. Ls for physical and chemical traits. Theor Appl Genet 102: 259-272

Stevens MA (1972) Citrate and malate concentration in tomato fruits: Genetic control and maturational effects. J Am Soc Hortic Sci 97: 655-658

Suzuki Y, Maeshima M, Yamaki S (1999) Molecular cloning of vacuolar $\mathrm{H}^{+}$-pyrophosphatase and its expression during the development of pear fruit. Plant Cell Physiol 40: 900-904

Suzuki Y, Shiratake K, Yamaki S (2000) Seasonal changes in the activities of vacuolar $\mathrm{H}^{+}$-pumps and their gene expression in the developing Japanese pear fruit. J Jpn Soc Hortic Sci 69: 15-21

Sweeney JP, Chapman VJ, Hepner PA (1970) Sugar, acid and flavor in fresh fruits. J Am Diet Assoc 57: 432-435

Takanokura Y, Komatsu A, Omura M, Akihama T (1998) Cloning and expression analysis of vacuolar $\mathrm{H}^{+}$-ATPase $69-\mathrm{kDa}$ catalytic subunit cDNA in citrus (Citrus unshiu Marc.). Biochim Biophys Acta 1414: 265-272

Terrier N, Deguilloux C, Sauvage FX, Martinoia E, Romieu C (1998) Proton pumps and anion transport in Vitis vinifera: The inorganic pyrophosphatase plays a predominant role in the energization of the tonoplast. Plant Physiol Biochem 36: 367-377

Terrier N, Sauvage FX, Ageorges A, Romieu C (2001) Changes in acidity and in proton transport at the tonoplast of grape berries during development. Planta 213: 20-28

Tucker GA (1993) Introduction. In: Seymour GB, Taylor JE, Tucker GA (eds) Biochemistry of Fruit Ripening. Chapman and Hall, London, pp 3-43

Unger EA, Hand JM, Cashmore AT, Vasconcelos AC (1989) Iso- 
lation of a cDNA encoding mitochondrial citrate synthase from Arabidopsis thaliana. Plant Mol Biol 13: 411-418

Visser T, Verhaegh JJ (1978) Inheritance and selection of some fruit characters of apple. 1. Inheritance of low and high acidity. Euphytica $27,753-760$
Yoshida M (1970) Genetical studies on the fruit quality of peach varieties. I Acidity. Bull Hortic Res Stn Jpn Series A 9: 1-15 